\title{
Apocrine Metaplasia
}

National Cancer Institute

\section{Source}

National Cancer Institute. Apocrine Metaplasia. NCI Thesaurus. Code C8359.

A morphologic finding indicating the alteration of the glandular acinar epithelial cells to apocrine sweat gland cells. 